\title{
ENHANCING ONLINE LEARNING FOR PUBLIC HEALTH GRADUATE STUDENTS
}

\author{
Dulce Maria Ruelas, Grand Canyon University
}

\section{ABSTRACT}

The use of Web 2.0 tools in an online graduate public health program is an opportunity to further engage students with supporting technology and enhance the reflexivity and satisfaction of the student and instructor dyad. This reflective practice summary article discusses the use of Flipgrid and Loom as tools to further describe assignments and navigation of the public health community. A decision tree was created and used to evaluate which Web 2.0 tool was most appropriate in the first two courses of the Master of Public Health (MPH) program. After a trial and error period, the results demonstrated a clear distinction between the first two courses of the program. Based on the needs of the student and alignment with public health curriculum, Loom is better suited for the initial course and Flipgrid for the second course. Further assessment of these tools and evolving technology advancement on embedding videos can be made to assess retention rates in these courses.

\section{STATEMENT OF PROBLEM}

There is an underlying problem for graduate students initiating an online program related to use and effectiveness. This unspoken challenge, in addition to learning, relearning, or unlearning material for the graduate program, can become cumbersome and overbearing for students. Therefore, I decided to add Web 2.0 tools to two courses in the Master of Public Health (MPH) program.

I initiated teaching in the old MPH curriculum without the use of Web 2.0 tools or any technology. I continuously noted the low level of engagement and lack of questions. I began searching for a tool I could utilize to further explain public health concepts, in addition to the course materials and book.

The MPH curriculum endured a curriculum change and upgrade, which provided the opportunity to initiate new opportunities to engage with students and provide different capacity for building the online learning community of public health. As a new instructor and current student in an online postdoctoral program, I saw a gap in interactions for this distance learning program. I can relate to the students' experiences because of my own enrollment as an online student. I understand that an instructor also serves as a mentor, tutor, and supporter of the student's academic journey. I could relate to the importance of how technology matters and how it is impacting my desire to participate and further engage in the online platform.

\section{STATEMENT OF PURPOSE}

The general approach I chose was to use technology in the new MPH curriculum with students that had not been a part of the old curriculum. I selected courses I was already teaching and integrated purposeful technology in aspects of the course I had previously noted. The use of the first two courses in the MPH Program seemed practical to incorporate Web 2.0 tools

The first two courses are PUB-510 Foundations of Public Health and PUB-520 Social and Behavioral Principles of Public Health. PUB-510 reviews key concepts and or refreshes the memory for those reengaging into online learning. Therefore, students' needs can be met on different levels. This is not only a selling point of the MPH program, but also an opportunity for the student to self-assess if this degree program is of their interest. PUB-510 is a four-week course, which is a unique characteristic of the MPH program. PUB-520 reviews theories 
and models utilized in public health and is an eightweek course.

PUB-510 is the initial course and the foundation for the program. It is in the best interest of the instructor to engage the student as much as possible as this is the deciding point for the student to continue or think about if the MPH is a good fit for them. The dedication of the student in the next course is eight weeks; one month is not much investment. Therefore, having the nonpublic health major students fully understand and comprehend the initial material is vital.

The practice of using Web 2.0 tools is a reflection of the dedication and investment of the instructor. I did not reuse the videos for the different sections of the course, because each section of the course is different from the next. Instead, I utilized the time to remake each weekly video to cater to the students.

\section{ACTIVITY/PROJECT DESCRIPTION}

Flipgrid is a Web 2.0 technology tool where educators and student alike create short videos shareable by logging onto a grid or link password personalized. Loom is an additional communication recording tool that has different video options. The three video options are to share a screen with audio, a screen with audio, and the instructor's face or just audio without the screen. Additionally, Loom has the option for the student to leave comments and select emojis as remarks to the video. Students can be anonymously utilizing an alias when deciding to leave a comment or remark.

To assess which Web 2.0 tool was appropriate for each of the courses, I initiated the use of both Flipgrid and Loom. I used Flipgrid in two courses of PUB-510 and PUB-520. When I was going to use it for the fourth time, I saw that Flipgrid changed their format from three minutes of video recording to a maximum of one and a half minutes. The change altered the practice because I had less time to use to review course material. My perceptions of change were not able to be confirmed with student engagement as there was no difference noted or comments at the end of course survey (EOCS). That is how I concluded the recommendation that Flipgrid is used as a Web 2.0 tool more toward the middle of the program because of the availability of video recording options when compared to Loom.

Both PUB-510 and PUB-520 students provide feedback by answering the following prompt in the

Table 1. Web 2.0 tools comments from PUB-510 and PUB-520 courses

\begin{tabular}{|c|c|}
\hline Loom: PUB-510 & Flipgrid: PUB-520 \\
\hline $\begin{array}{l}\text { "Yes I watched the loom videos. The videos were helpful but some of the } \\
\text { contents were not easy to access. I would continue to view the videos if it } \\
\text { is provided." }\end{array}$ & $\begin{array}{l}\text { "Professor, I enjoyed your way of communicating with us via Flipgrid, I never } \\
\text { could reply you on the video, but I did check almost every week, it was a good } \\
\text { start of week summary each week truly" }\end{array}$ \\
\hline $\begin{array}{l}\text { "I watched the videos on loom and I can honestly say I felt a bit relieved } \\
\text { knowing that you're real and appreciated that you took the time to go over the } \\
\text { course material. I feel it makes this whole online learning a bit more personal } \\
\text { than just having written instructions on the screen. Having you describe the } \\
\text { assignments and covering certain topics for the week made me feel more } \\
\text { comfortable because for me this online learning is such a new experience." }\end{array}$ & $\begin{array}{l}\text { "I did watch all of the videos, they we're very helpful. They gave good } \\
\text { introduction to each week. I really enjoyed it and liked the picture } \\
\text { communication." }\end{array}$ \\
\hline $\begin{array}{l}\text { "I watched one Loom video this course, the one where you described how to } \\
\text { complete the week } 2 \text { assignment and it was very helpful. Thank you." }\end{array}$ & $\begin{array}{l}\text { "Yes, Yes. It was good to hear from you and get an overview of the subject for } \\
\text { the week." }\end{array}$ \\
\hline "Yes, I watched all the videos. It was very helpful to me. Thankyou." & $\begin{array}{l}\text { "Yes, yes. It was really helpful and convenient hearing from you and also } \\
\text { putting a face to the name." }\end{array}$ \\
\hline \multirow[t]{3}{*}{$\begin{array}{l}\text { "Yes, I watched all the Loom videos, it was definitely helpful, you explained } \\
\text { what we need to do and to you showing us it, it was the best part." }\end{array}$} & $\begin{array}{l}\text { "Yes. I watched all the Flipgrid videos and they helped me to comprehend } \\
\text { what the Professor expected me to do each week. The information in the } \\
\text { Flipgrid was brief, precise and gave me confidence all my posts each week. } \\
\text { Thank you, God bless." }\end{array}$ \\
\hline & $\begin{array}{l}\text { "Yes, yes it was very helpful. It gave you a clear understanding of what the } \\
\text { assignment was and what was expected." }\end{array}$ \\
\hline & "Yes, I've watched all the videos posted. I personally think they were helpful." \\
\hline
\end{tabular}


online platform as an announcement for either use of Loom and Flipgrid:

One last item. I would like for you to take the time and respond to this post and answer the following questions to continue to enhance your online experience:

1. Did you watch at least one video this course? Yes or No

2. If you watched at least one video, was it helpful? Yes or No

3. If you did not watch at least one video, why not? Answer candidly.

I appreciate your assistance. Thank you for taking the time to respond, this helps me as an instructor and for your future colleagues enrolled in this course.

Table 1 provides examples of feedback received from students.

In addition to these comments via the course platform, I reviewed the Loom comments and emojis, along with the number of views. I found that in both PUB-510 and PUB-520 courses, there were a consistent more than six views for each video. Loom offers an option to the instructor to review who viewed the video even when the student would like to remain anonymous. Additionally, I had turned on a notification to inform me when a student viewed and or left a comment. The return on investment from an instructor point of view is to know that as soon as a video is posted, student(s) are viewing. As for emoji remarks, consistent clapping hands or a "thumbs up" would be added to the videos. The options for emojis in Loom are smiley crying face, heart face, shocked face, clapping hands, thumbs up, or thumbs down.

\section{REASONS FOR THE PROBLEM}

The unknown of this new integrated practice was not being able to anticipate how students would react to the use of Loom and Flipgrid with the initial implementation. The first implementation was a trial and error, but this became easier as more courses were added to the queue of use. As an instructor, the vulnerability of disseminating information that can be downloaded and re-used, and re-shared easily and quickly, can be beneficial. Students can re-review and scroll through a video to specific points of interest, which can lessen frustrations when concepts or topics are challenging (Kahn, Everington, Kelm, Reid, \& Watkins, 2017).

Moreover, I had to teach myself to the use of these tools. Learning how to utilize Loom and Flipgrid, and the intricacies of providing a link for students to leave the university platform, can be a barrier. However, I had to trust that students would make the effort to view the video(s). In addition, I had to acknowledge that the online learner desires interaction; by incorporating asynchronous interactions with a video that had both the instructor's voice and image made a shift for both the student and me.

\section{EVALUATION OF REASONS FOR THE PROBLEM}

Online learning is now being considered a more effective platform for the graduate learner than that of a traditional setting (Gemmell \& Harrison, 2017). Being able to be a part of this effectiveness has benefits for both the student and the instructor. The benefits include making the online process adaptable to an individual's learning. There are two key aspects that contribute to the learning process: technical and environmental. Then there are two characteristics: personal and learner (Kahn et al., 2017). When you combine the factors and characteristics, this creates optimal performance. When an instructor can provide aspects of each of these factors and characterize the behavior changes for a better grade it can result in the behaviors that lead to seeking help to obtaining a higher grade.

The innovation of the utilization of technology such as these Web 2.0 tools provides an enhanced and shared experience between the instructorand student. Theneed forcapacity building for public health courses has been demonstrated across countries successfully (Madhok, Frank, \& Heller, 2018); therefore, the need exists to continue it. Research from Kahn et al. (2017) suggested that the need for student engagement in the online platform goes beyond being useful, but is linked to reflexivity and retention. The social interactions that can be created on behalf of the instructor through the use of technology are more meaningful. The instructor has the opportunity to create an optimal environment for the reflexivity. Kahn et al. (2017) described reflexivity as the way an individual 
contemplates the social setting and is able to relate to it.

\section{DECISION}

The decision to continue with the use of technology in the two public health courses was based on what Dewey (1989) refers to as changing the atmosphere. Students took the time to respond to the request for comments, in addition to using the emojis of Loom. The impact and reflexivity that Loom and Flipgrid created in the students' learning environment, even within a small sample of students, was enough for me as an instructor to encourage its use; however, I did use a decision tree method to formally asses the use of the tools (See figure 1).

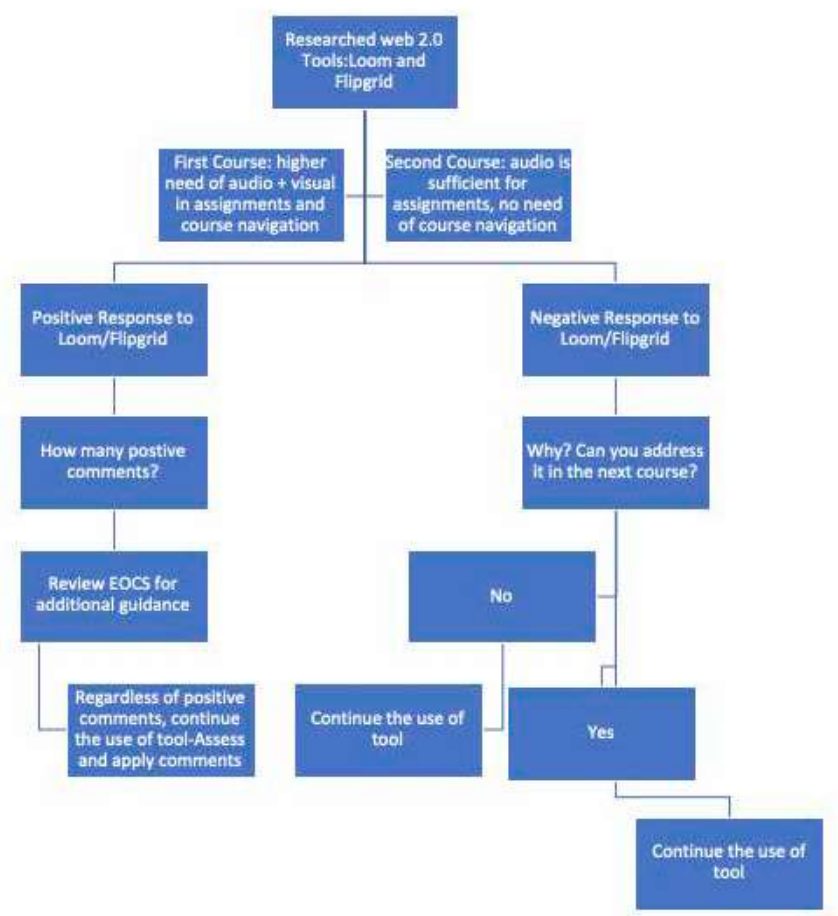

Figure 1. Decision tree on the use of Web 2.0 tools with the courses in the new MPH curriculum.

\section{REFLECTIVE CRITIQUE}

This reflective practice can help inform other instructors that are on the verge of decision making between different Web 2.0 tools. All tools are helpful; however, the more one gets to use and become familiar with the nuances of each, the more one can cater to its use. PUB-510 students have a higher need for engagement and transition; hence why I decided to utilize Loom. This can serve in use to other instructors that are teaching initial courses.
As for Flipgrid, I found that students in the second course engaged with my audio and visual. I talked less in each video and was able to become better at intentional videos because of the time limitations. I comprehend the working and busy student that is trying to progress academically. By providing the student to view Flipgrid videos off their phone, the technology use at their fingertips was better.

Also, it is my perspective that first-course students have a different need than any other course in the MPH program. The online learner needs to feel connected to an institution, a real instructor as the choice of the graduate program becomes a reality. Once videos are utilized, the technology transforms the course into a social community (Weidlich \& Bastiaens, 2018). Technology creates the image of the instructor that can be personalized and is connected to the course and the student all in one video. Hence, when the instructor is contacted there is a voice and picture the student can relate to.

Moreover, the use of Loom provides a lecturestyle ability that better informs the formality of the graduate program. The commitment of the student increases, and the learning environment capacity is enhanced. As an instructor, I have come to the conclusion based on my experience, the motivation of the student is two-fold: internal motivation and instructor-led motivation. Once the student can selfregulate and find the continuous motivation to abide by online learning regulations, the student seeks instructor engagement. The instructor engagement can be found in feedback and discussions, with which it creates and may imitate the same level of commitment to the course as the student.

Future recommendations include the use of Flipgrid and Loom in the last two courses of the program. As students' progress through the online program do they still need one-on-one direction and clarification of course materials via audio and visual Web 2.0 tools? How does the online student transform and grow in 24 months? Also, there were different technological advancements in the online platform for the university, which allowed for embedding of audio and videos. This changes the dynamic of engagement of students, which has the potential for further research. 


\section{References}

Dewey, J. (1989). The later works of John Dewey, 1825-1953: Essays and how we think. J. A. Boydston (Ed). Carbondale and Edwardsville, IL: Southern Illinois University Press.

Gemmell, I. \& Harrison, R. (2017). A comparison between national and transnational students' access of online learning support materials and experience of technical difficulties on a fully online distance learning Master of Public Health programme, Open Learning: The Journal of Open, Distance and e-Learning, 32(1), 66-80. doi:10.1080/02680513.2016.12 53463

Kahn, P., Everington, L., Kelm, K., Reid, I., \& Watkins, F. (2017). Understanding student engagement in online learning environments: The role of reflexivity. Educational Technology Research \& Development, 65(1), 203-218. doi:10.1007/ s11423-016-9484-z

Madhok, R., Frank, E., \& Heller, R. F. (2018). Building public health capacity through online global learning. Open Praxis, 10(1), 91-97. doi: 10.5944/openpraxis.10.1.746

Weidlich, J., \& Bastiaens, T. J. (2018). Technology matters-the impact of transactional distance on satisfaction in online distance learning. International Review of Research in Open and Distributed Learning, 19(3), 222-242. 